\title{
JUNIOR NATURALISTS
}

This month we are lucky enough to have another letter from a junior. Thankyou Fred - maybe you can get some of your friends to write us also about their nature and outdoors experiences.

\section{AT McBRIDE LAKE}

When I was at Lake McBride I saw two of your associates. It was about 10 o'clock, I was walking on the beach and I came about two feet in front of a Beaver on the beach. It was dark so he couldn't see me. About an hour before I saw the Beaver out 5 feet in the water.

The next morning Dale and Paule Hjertaas and I went on a canoe trip. We saw Beaver, Muskrats, ducks, crayfish and other birds and animals. They also taught me some things about canoeing. I enjoyed it with them! Thank-you Dale and Paule. - Fred Kakish, Box 211, Foam Lake, Sask. SOA 1 AO

\section{PHOTO CONTEST RESULTS}

We did get some entries in the junior photo contest. We chose two winners who will both receive a $\$ 10.00$ gift certificate from the Blue Jay Bookshop. Here are the pictures. Maybe we could get a short story from the winners about these pictures in the next issue of the Blue Jay.

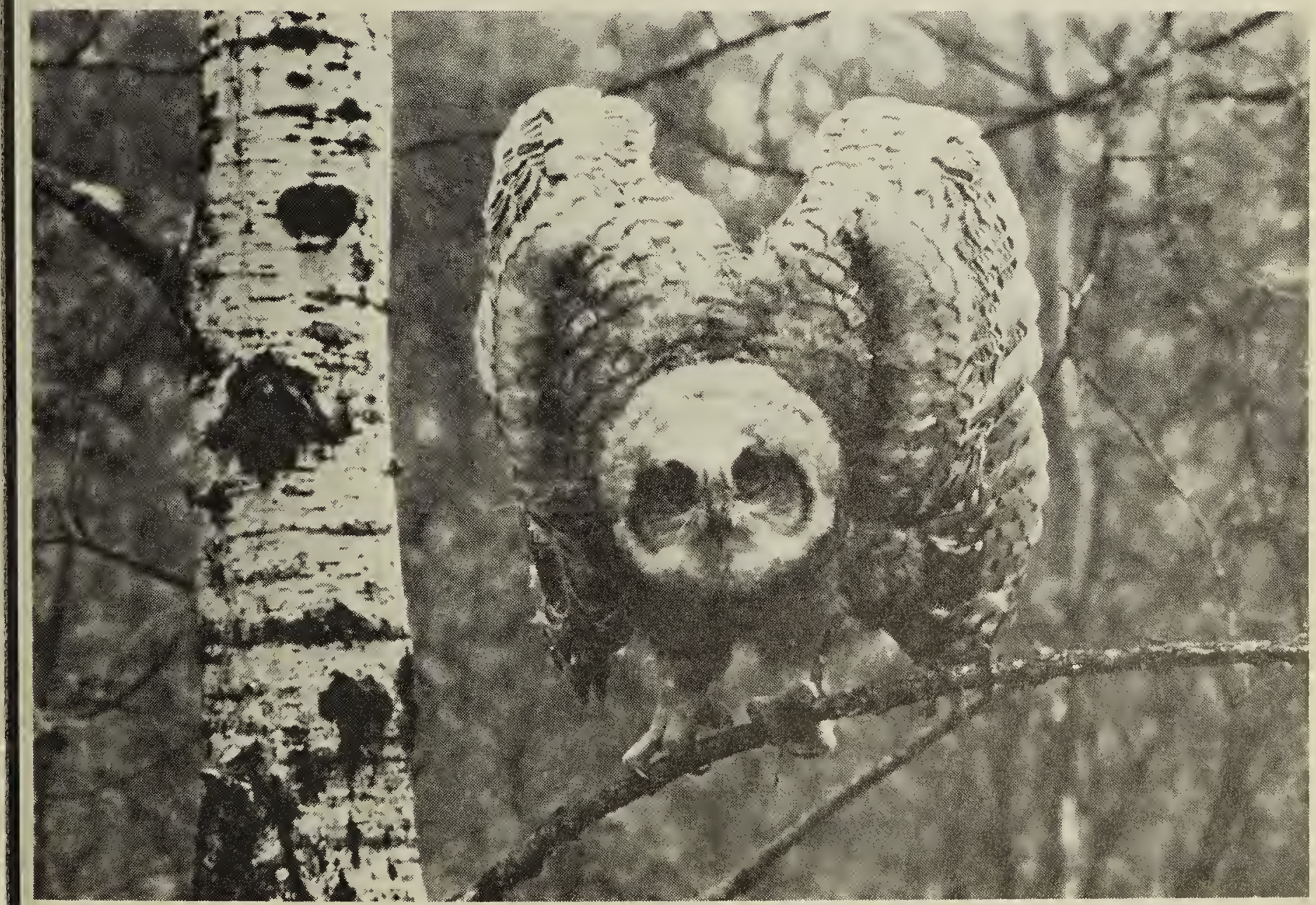




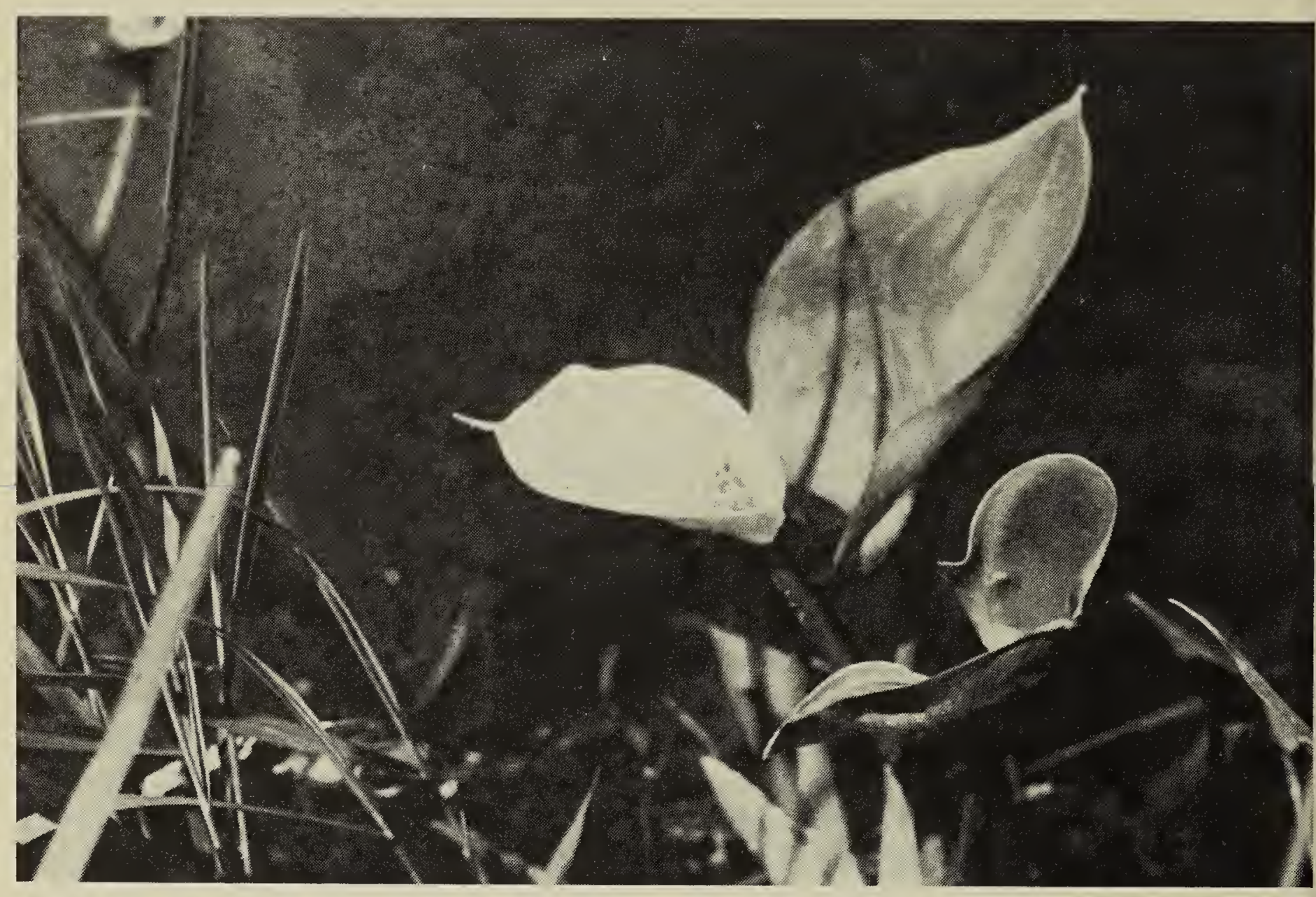

Calla Lily.

Nigel Caulkett

\section{ENERGY}

A topic suitable for the long winter season is energy. How to conserve it, mainly. Now, maybe you will tell me that you have heard a lot about it already but, have you ever thought about energy as it relates to the natural world?

Energy is what keeps everything and everyone going. If you don't eat enough, you are hungry and tired, you have less energy. If you run a lot, you burn energy. For us, it does not matter as much as for animals outside because, when we get home, we always have enough high energy food to eat to build back that energy. And also, we are warm in our houses, so we don't have to spend energy shivering or being constantly on the go just to keep warm.

In winter, energy conservation is important for every animal too.

Ground Squirrels and Prairie Dogs hibernate in their tunnels under ground. The temperature is never as low in the ground as outside, so they don't have to spend as much energy keeping warm. Also, hibernating means being in a torpor, with lowered body processes. It's like living in slow motion. If you keep one as a pet and don't let it hibernate, it will die much younger.

Deer, from spring to fall, eat with the purpose of putting on fat reserves that will help them go through the winter. The winter food is energy poor so, by the next spring, the deer will have used up all their fat reserves and, if the winter has been long and hard, be in poor condition. If a deer is disturbed and tracked by a snowmobile, it will run to get away, which will use 6 to 11 times more energy than normal. If it happens too often, this deer may die before the end of winter, of exhaustion and starvation. 
There should be here a warning for naturalists as well. In England, birdwatchers came in such numbers to see a rare bird that the poor animal dropped dead before their eyes, of harassment and exhaustion!

Another example of energy conservation is the arctic poppy. In the short summer of the tundra, it needs extra help to produce its seeds. It is actually helping itself by always turning to face the sun. Also, the area surrounded by the petals is black, which absorbs more heat. The temperature there can reach $10.5^{\circ} \mathrm{F}$ higher than air temperature so the seeds get a boost to mature.

Finally, a most unusual finding. Some insects actually make their own anti- treeze, glycol, so they can spend the winter unharmed by frost!

What about the role of furs, feathers, cover on animal survival? Why do some trees and smaller plants survive the winter here while ones from a warmer region cannot?

I am sure that you can think of other ways animals and plants conserve energy. Why don't you write the Blue Jay about it?

See you in the next newsletter with nature crosswords and quizzes. Paule B. Hjertaas, 919 Cook Crescent, Regina, Saskatchewan. S4X 2L9

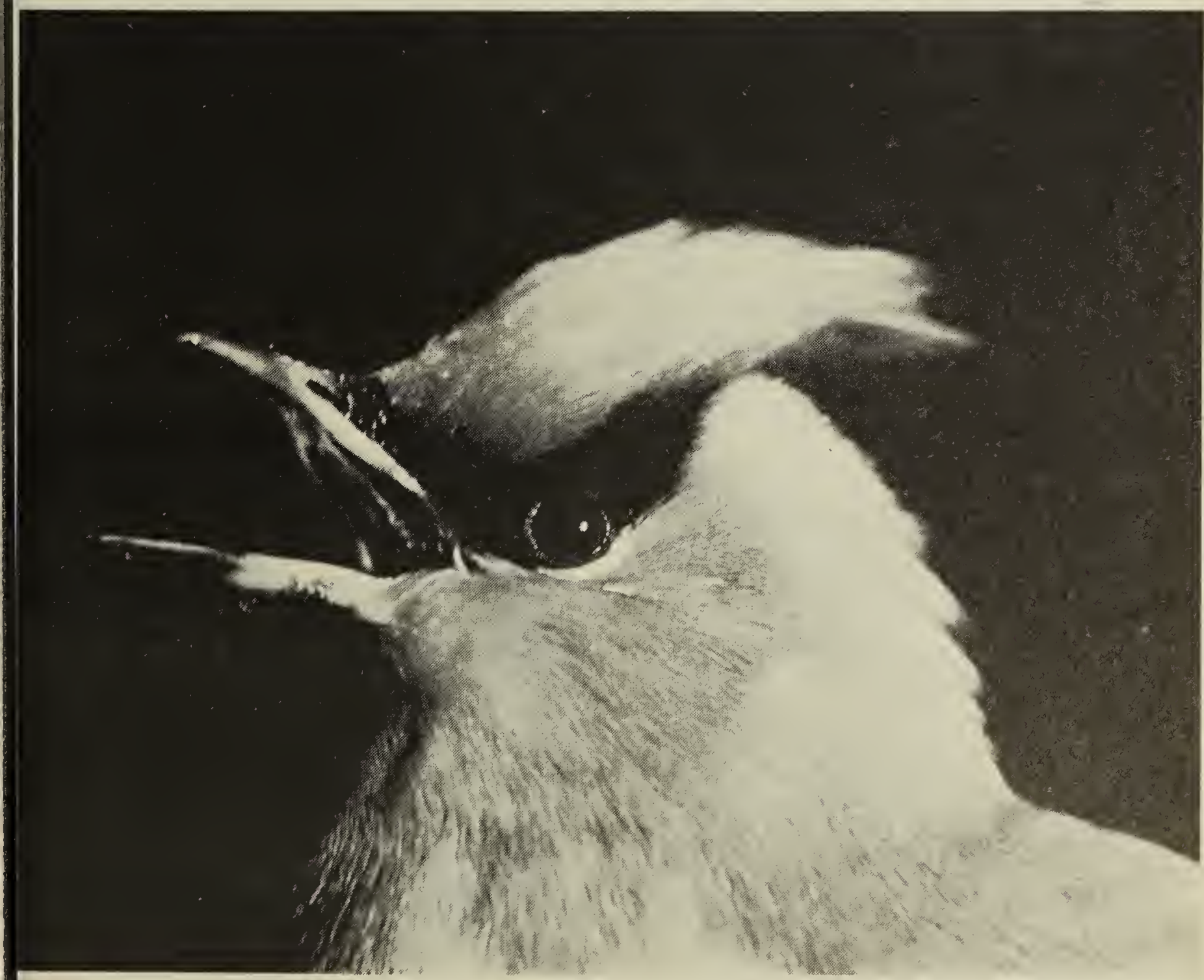

